\title{
A new species of snail-eating snakes of the genus Pareas Wagler, 1830 (Reptilia: Serpentes) from eastern Himalayas, India
}

\author{
Harshal BHOSALE ${ }^{1}$, Pushkar PHANSALKAR ${ }^{2}$, Mandar SAWANT ${ }^{3}$, \\ Gaurang GOWANDE ${ }^{4}$, Harshil PATEL ${ }^{5} \&$ Zeeshan A. MIRZA ${ }^{6, *}$ \\ ${ }^{1,3}$ Bombay Natural History Society, Mumbai, Maharashtra 400001, India. \\ ${ }^{2}$ A/2, Ajinkyanagari, Karvenagar, Pune, Maharashtra 411052, India. \\ ${ }^{4}$ Annasaheb Kulkarni Department of Biodiversity, Abasaheb Garware College, Pune, \\ Maharashtra 411004, India. \\ ${ }^{4}$ Department of Biotechnology, Fergusson College, Pune, Maharashtra 411004, India. \\ ${ }^{5}$ Department of Biosciences, Veer Narmad South Gujarat University, Surat, Gujarat 395007, India. \\ ${ }^{6}$ National Centre for Biological Sciences, TIFR, Bangalore, Karnataka 560065, India. \\ *Corresponding author: snakeszeeshan@gmail.com \\ ${ }^{1}$ Email: harshabhosale99@gmail.com \\ ${ }^{2}$ Email: pushkar.phansalkar@gmail.com \\ 32Email: m.sawant@bnhs.org \\ ${ }^{4}$ Email: gaurang.gowande@gmail.com \\ ${ }^{5}$ Email: harshilpate1121@gmail.com

\footnotetext{
${ }^{1}$ urn:1sid:zoobank.org:author:31CD74C9-4433-43D5-8132-1EF39AF0BDC3

${ }^{2}$ urn:1sid:zoobank.org:author:06BB8F0E-9623-4759-9CBB-44927E43D47A

${ }^{3}$ urn:lsid:zoobank.org:author:18DE73F8-DB9E-488D-97C1-D5CEC418B160

${ }^{4}$ urn:Isid:zoobank.org:author:1D0ED49C-6286-4E7E-AE14-C0EEB9DBBCAF

${ }^{5}$ urn:1sid:zoobank.org:author:DCDF105B-E163-4C8F-86C7-85C4275974EF

${ }^{6}$ urn:lsid:zoobank.org:author:25F673F0-3FB9-4A4F-81CE-997748CC26E6
}

\begin{abstract}
A new species of snail-eating snakes of the genus Pareas Wagler, 1830 is described from the eastern Himalayas. The species Pareas kaduri sp. nov. differs from all known species of the genus in bearing the following suite of characters: SVL 455-550 mm, TaL/TL 0.184-0.207, brown dorsum with black transverse bands throughout the body, 15 dorsal scale rows throughout the body and mid-dorsal vertebral scale rows enlarged, 8 rows keeled in males, loreal not touching orbit, ventrals 160-183, subcaudals 65-70 in males, 52 in one female specimen, hemipenis short, unilobed and 6-7 maxillary teeth. Molecular data for mitochondrial 16S rRNA and cytochrome $b$ genes further attest the distinctness of the new species, which was recovered as a member of the Pareas hamptoni clade. Our work brings the total number of species recognized within the genus Pareas to 20 .
\end{abstract}

Keywords. Arunachal Pradesh, biodiversity hotspot, $c y t$, Indo-Burma, molecular phylogeny, Pareidae, Pareas kaduri sp. nov., taxonomy. 
Bhosale H., Phansalkar P., Sawant M., Gowande G., Patel H. \& Mirza Z.A. 2020. A new species of snaileating snakes of the genus Pareas Wagler, 1830 (Reptilia: Serpentes) from eastern Himalayas, India. European Journal of Taxonomy 729: 54-73. https://doi.org/10.5852/ejt.2020.729.1191

\section{Introduction}

Members of the snake subfamily Pareinae Romer, 1956 are strictly nocturnal, arboreal and are one of the most fascinating groups of snakes that feed on rather unusual prey (Whitaker \& Captain 2004; Hoso et al. 2007; Vitt \& Caldwell 2014). Members of the subfamily that specialize in feeding on snails present a remarkable case of dietary specialization where they have asymmetry in their dentition on the maxilla to devour prey like snails and slugs (Hoso et al. 2007). Despite their evolutionary significance, these snakes remain poorly studied concerning their habits, habitat and their diversity. The subfamily currently comprises three genera, namely, Pareas Wagler, 1830, Aplopeltura Duméril, 1853 and Asthenodipsas Peters, 1864 (Deepak et al. 2018). The genus Pareas is the most species-rich among members of the subfamily, with 19 nominate species recognized today (Wallach et al. 2014; You et al. 2015; Vogel et al. 2020), with three species currently recorded from India, i.e., Pareas andersonii Boulenger, 1888, P. monticola Cantor, 1839 and P. modestus Theobald, 1868 (Whitaker \& Captain 2004; Lalbiakzuala \& Lalremsanga 2019; Vogel et al. 2020).

In the course of a herpetological expedition, we surveyed several localities across the northeastern Indian state of Arunachal Pradesh. During the surveys, we collected specimens of Pareas which looked visually similar to each other that were later identified to belong to two sympatric species based on the structure of the hemipenis. One population was attributed to the species $P$. monticola based on ventral scale number and lack of keels on dorsal scales and shape of hemipenis. The other, however, could not be attributed to any of the species reported from India, owing to the differences in scalation and hemipenis morphology. To identify the second population that was collected from near Kamlang Wildlife Sanctuary in eastern Arunachal Pradesh, we generated molecular data for the collected specimens and compared them with available museum material. Results from the molecular analysis show that the specimens are genetically distinct form congeners and comparison of morphology of known species further attests the findings. We herein describe the population of Pareas from eastern Arunachal Pradesh as a new species following an integrative taxonomic approach incorporating morphological, osteological and molecular data.

\section{Material and methods}

\section{Morphology}

The study was conducted under permit nos. CWL/Gen/173/2018-19/Pt.V11/2434-43 and CWL/ Gen/173/2018-19/Pt.V11/2421-33 issued by the Forest Department of Arunachal Pradesh. Four specimens of the new species were collected in the field by hand, photographed and later euthanized with halothane within 24 hours of capture following ethical guidelines for animal euthanasia (Leary et al. 2013). The specimens were fixed in $8 \%$ formaldehyde buffer and later stored in $70 \%$ ethanol. Liver tissue was collected for molecular work and stored in $95 \%$ molecular grade ethanol prior to fixation. The specimens have been deposited in the collection of the Bombay Natural History Society (BNHS), Mumbai, and research collection at the National Centre for Biological Sciences, Bangalore. Measurements were taken with the help of a digital calliper to the nearest $0.1 \mathrm{~mm}$, except SVL and TaL, which were taken with a string and then measured using a scale.

Morphological data for the new species were compared with the type specimens available for examination and other voucher specimens of the congeners and with data from Vogel (2015) and You et al. (2015). Dentition asymmetry index was calculated following Hoso et al. (2007). 


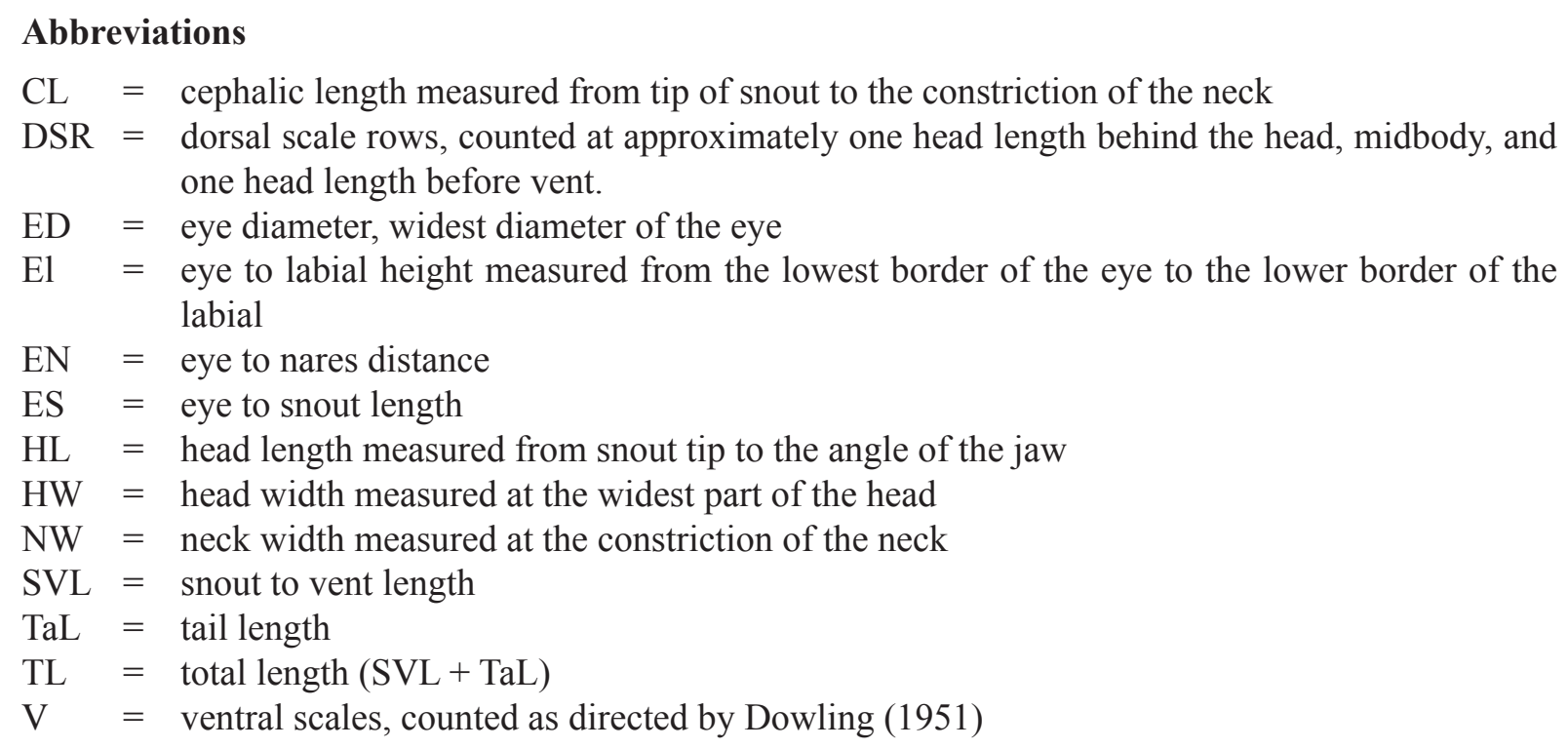

\section{Repositories}

BNHS $=$ Bombay Natural History Society, Mumbai, India

MNHN = Muséum national d'histoire naturelle, Paris, France

NCBS $=$ Collection Facility of the National Centre for Biological Sciences, Bangalore, India

NHMUK $=$ Natural History Museum, London, UK

ZSI $\quad=$ Zoological Survey of India, Kolkata, India

Micro-CT scans were generated for the paratype male NCBS BH655 using a Bruker ${ }^{\circledR}$ Skyscan 1272 (Bruker BioSpin Corporation, Billerica, Massachusetts, USA). The head of the specimen was scanned for 210 minutes at a resolution of $5.4 \mu \mathrm{m}$ and recording data for every $0.4^{\circ}$ rotation for $360^{\circ}$ with (AL) $1 \mathrm{~mm}$ filter. The source voltage for the scan was $65 \mathrm{kV}$ and source current was $153 \mathrm{uA}$. Volume rendering was performed with CTVox (Bruker BioSpin Corporation) and images were edited in Adobe Photoshop CS6. Osteological description is based on volume renders retrieved from CTVox following the terminology of the skull described by Heatwole (2009). Images from CT scans of the new species were compared with existing literature on dentition of Pareas spp. (Wang et al. 2020) and with CT scan images of museum specimens (Anonymous 2015). Comparative material examined is listed in Appendix 5.

\section{Molecular analysis}

Genomic DNA was isolated from the preserved tissues of the holotype and the female paratype and a specimen of P. monticola from Kamlang WLS and from near Pakke Tiger Reserve using QIAGEN DNeasy kits following protocols directed by the manufacturer. Molecular methods largely follow Mirza et al. (2016) and Mirza \& Patel (2018). A fragment of the mitochondrial cytochrome b (cyt b) and 16S rRNA were amplified using primers used by Pyron et al. (2013) and Mirza et al. (2016). A $22.4 \mu 1$ reaction was set, containing $10 \mu \mathrm{l}$ of Thermo Scientific DreamTaq PCR Master Mix, $10 \mu$ l of molecular grade water, $0.2 \mu \mathrm{l}$ of each $10 \mu \mathrm{M}$ primer and $2 \mu \mathrm{l}$ of template DNA, carried out with an Applied Biosystems ProFlex PCR System. The thermo-cycle profile used for amplification was as follows: $95^{\circ} \mathrm{C}$ for 3 minutes, (denaturation temperature $95^{\circ} \mathrm{C}$ for 30 seconds, annealing temperature $48^{\circ} \mathrm{C}$ for 45 seconds for $c y t b$ as well as $16 \mathrm{~S} \mathrm{rRNA}$, elongation temperature $72^{\circ} \mathrm{C}$ for 1 minutes) $\times 36$ cycles, $72^{\circ} \mathrm{C}$ for 10 minutes, hold at $4^{\circ} \mathrm{C}$. PCR product was cleaned using a QIAquick PCR Purification Kit and sequenced with an Applied Biosystems 3730 DNA Analyzer. Sequences of related taxa available from GenBank ${ }^{\circledR}$ were downloaded for molecular phylogenetic reconstruction following taxa sampling as in Wang et al. (2020) (Appendix 1), 
and the sequences were aligned in MegaX (Kumar et al. 2018) using ClustalW (Thompson et al. 2002) with default settings. The aligned dataset was subjected to Maximum Likelihood (ML) and Bayesian Inference (BI) on the online portal of W-IQ-TREE at http://iqtree.cibiv.univie.ac.at/ (Trifinopoulos et al. 2016). The model selection for the analysis was set to auto and the analysis was run with an ultrafast bootstrap analysis for 1000 iterations. Non-parametric bootstrap pseudo-replicates were used to assess support of the clades. For the optimal partitioning strategy and evolutionary substitution model, aligned data was analyzed using PartitionFinder ver. 1.1.1 (Lanfear et al. 2012), implementing a greedy search algorithm under the Akaike Information Criterion (AIC). Bayesian Inference (BI) was implemented in MrBayes ver. 3.2.2 (Ronquist \& Huelsenbeck 2003) and was run for 10 million generations and sampled every 1000 generations. The BI run included five parallel chains, three hot and two cold chains. The standard deviation of split frequencies of the analysis reached were below 0.01 , after which the analysis was not continued further. Twenty-five percent of the trees generated were discarded as burn-in. Data were subjected to phylogenetic reconstructions with a generalised time-reversible (GTR) + gamma (G) model as the sequence substitution model, based on the optimal partitioning scheme suggested by PartitionFinder for BI. Un-corrected pairwise p-distance (\% sequence divergence) was calculated in MegaX (Kumar et al. 2018) with pairwise deletions of missing data and gaps.

\section{Results}

Molecular phylogenetics based on 1117 bp of the mitochondrial cytochrome $b$ gene revealed that the specimens from eastern Arunachal Pradesh were embedded in a clade containing P. hamptoni (Boulenger, 1905), P. mengziensis Wang et al., 2020 and P. formosensis (Van Denburgh, 1909), and was recovered basal to the entire clade with high support (ML bootstrap 89, BI posterior probability 0.99). Genetic divergence with congeners is $12-24 \%$. Keeled dorsal scales and hemipenis morphology further support the distinctness of the species from other members of the clade and congeners (see below). Molecular phylogeny based on 16S rRNA recovered similar relationships as with cyt $b$.

Class Reptilia Laurenti, 1768

Order Squamata Oppel, 1811

Suborder Serpentes Linnaeus, 1758

Family Pareidae Romer, 1956

Subfamily Pareinae Romer, 1956

Genus Pareas Wagler, 1830

Pareas kaduri sp. nov. urn:lsid:zoobank.org:act:66902402-DD58-4F83-B8B2-381EC46FA395

Figs 1-5, Table 1

\section{Differential diagnosis}

A new species of Pareas bearing the following suite of characters: (1) SVL $455-550 \mathrm{~mm}$, (2) TaL/ TL $0.184-0.207$, (3) 15 dorsal scale rows (DSR) throughout body and mid-dorsal vertebral scale rows enlarged, 8 rows keeled in males, (4) loreal not touching orbit, (5) ventrals 160-183, (6) subcaudals 65-70 in males, 52 in one female specimen, (7) hemipenis short, unilobed, (8) 6-7 maxillary teeth, (9) dorsum brown with thin black transverse bands, the head with a large black blotch from which two longitudinal black stripes (3-4 scales wide) run on each side of the neck leaving a pale central portion.

The new species is here compared with congeners based on non-overlapping and differing characters: vertebral scales enlarged (vs not enlarged in P. chinensis (Barbour, 1912), P. macularius Theobald, 1868, P. margaritophorus (Jan 1866), P. vindumi Vogel, 2015); loreal not in contact with orbit (vs in contact in P. boulengeri (Angel, 1920), P. monticola (Cantor, 1839), P. stanleyi (Boulenger, 1914), P. vindumi) and Amblycephalus yunnanensis Vogt, 1922; eight mid-dorsal vertebral scales keeled (all scales smooth 
in P. boulengeri and Amblycephalus kuangtungensis Vogt, 1922, 9-13 keeled dorsal scales in P. komaii (Maki, 1931), 3-5 in P. modestus); two anterior temporals (vs one in P. nigriceps Guo \& Deng, 2009); ventrals 160-183 (vs 195-213 in P. nuchalis (Boulenger, 1900), 189-194 in P. iwasakii (Maki, 1937), 151-160 in P. stanleyi, 190-196 in P. monticola, 130-160 in P. margaritophorus), 6-7 maxillary teeth (vs 4-5 in P. chinensis (Barbour, 1912) and P. boulengeri, 3-5 in P. menglaensis Wang, Che, Liu, Li, Jin, Jiang, Shi \& Guo, 2020); prefrontals in contact with orbit (vs not in contact in P. carinatus (Boie, 1828)); subcaudals 65-70 in males, 52 in female (vs 71-79 in P. atayal You, Poyarkov \& Lin, 2015, 37-45 in $P$. andersonii); single nasal (vs two in $P$. nuchalis and $P$. stanleyi); dentition asymmetry index 4.55 in males (13.51 in P. komaii, 29.03 in P. atayal).

The new species shares several characters with members of its clade and is here compared to each species in greater detail based on differing and non-overlapping characters. The new species differs from P. formosensis in bearing keeled dorsal scales (vs smooth in P. formosensis), dentition asymmetry index 4.55 in males (vs 16.13 in P. formosensis).

The new species differs from P. mengziensis Wang, Che, Liu, Li, Jin, Jiang, Shi \& Guo, 2020 in bearing 6-7 maxillary teeth (vs 3-5 in P. mengziensis) and in having the dorsum with thin black bands (vs connected black reticulations throughout the body in $P$. mengziensis).

The new species is most similar to P. hamptoni in sharing the plesiomorphic state, where the loreal shield does not touch the orbit and is separated by the preocular. However, the new species differs from the species as follows: ventrals 160-183 (vs 197-202); two anterior temporals (vs a single temporal scale in P. hamptoni); subcaudals 65-70 in males, 52 in female (vs 96 in P. hamptoni); bearing 8 keeled dorsal scales (vs only a single row keeled in P. hamptoni); hemipenis unilobed and not forked (vs deeply forked in P. hamptoni).

\section{Etymology}

The specific epithet is a patronym honoring wildlife photographer Sandesh Kadur for his contribution to biodiversity documentation in the Himalayas, in particular Arunachal Pradesh, as well as for his constant support to the authors during the expedition.

\section{Type material}

\section{Holotype}

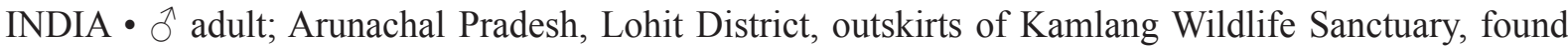
along the road leading to Hawa camp from Parshuram Kund; $27.880711^{\circ} \mathrm{N}, 96.363239^{\circ} \mathrm{E} ; 350 \mathrm{~m}$ a.s.1. (Datum WGS84); 23 Jul. 2019; Harshal Bhosale, Mandar Savant, Pushkar Phansalkar and Gaurang Gowande leg.; BNHS 3574.

\section{Paratypes}

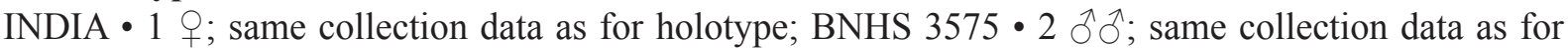
holotype; 28 Jul. 2019; Zeeshan Mirza, Harshal Bhosale, Mandar Savant, Pushkar Phansalkar and Gaurang Gowande leg.; NCBS BH655-BH656.

\section{Description}

\section{Holotype $\widehat{\jmath}$ (BNHS 3574) (Figs 1-4)}

The specimen is in good condition, preserved in a coil with its head resting outside the coil (Fig. 2). The specimen bears incisions. The hemipenis is partly everted.

Head short, $15.45 \mathrm{~mm}$ comprising $2.22 \%$ of total length; high, $6.47 \mathrm{~mm}$, with steeply domed snout in lateral view; upper jaw visible from ventral side. Head distinctly broader $(9.3 \mathrm{~mm})$ than neck $(4.4 \mathrm{~mm})$. 
Snout abruptly tapers, rounded tip in dorsal view (Fig. 3). Rostral subpentagonal, reaching top of the snout; as wide as high with a distinct furrow towards its ventral edge. Upper jaw distinctly longer than lower jaw. Nostrils large, 2.04 long and 1.32 high in the centre, elliptical-shaped, positioned in the centre and posterior half of nasal scale. Paired internasals, wider $(2.07 \mathrm{~mm})$ than long $(1.26 \mathrm{~mm})$; smaller than prefrontals. Prefrontals slightly wider $(2.83 \mathrm{~mm})$ than long $(2.59 \mathrm{~mm})$. Frontal hexagonal, $3.87 \mathrm{~mm}$ at the widest portion, median length $5.06 \mathrm{~mm}$. Parietals $6.62 \mathrm{~mm}$ long, $3.87 \mathrm{~mm}$ at its widest anteriorly. Temporals $2+3+3$ on both sides, subequal in size, posterior one inserts deeply between supralabial sixth, seventh and eighth. Five nuchal scales, slightly larger than adjacent dorsal scales, bordering parietals. Supraocular larger than preocular; preocular small, subequal. Loreal slightly longer $(1.68 \mathrm{~mm})$ than high $(1.54 \mathrm{~mm})$. Two postoculars, subequal in size. Eye large, circular, $3.13 \mathrm{~mm}$ (eye diameter/head height 0.48 ) diameter with a spherical pupil. Seven supralabials, seventh longest. First to third supralabials smallest, first supralabial only contacts second supralabial, rostral and nasal. Second supralabial in contact with nasal, preocular, loreal and first and third supralabials. Third supralabial in contact with preocular, second and forth supralabials and making contact remotely with loreal. Supralabials separated from the orbit by a crescent-shaped subocular.

Mental short, broad, triangular. Infralabials 7, anterior five infralabials short and narrow, fifth onwards larger. First infralabials of both sides in broad contact, separate the mental from the genials. Sixth infralabial broadest. First six infralabials in contact with the genials. Anterior genials almost twice as long as wide; anterior genials in broad contact, posterior genials only in remote contact.

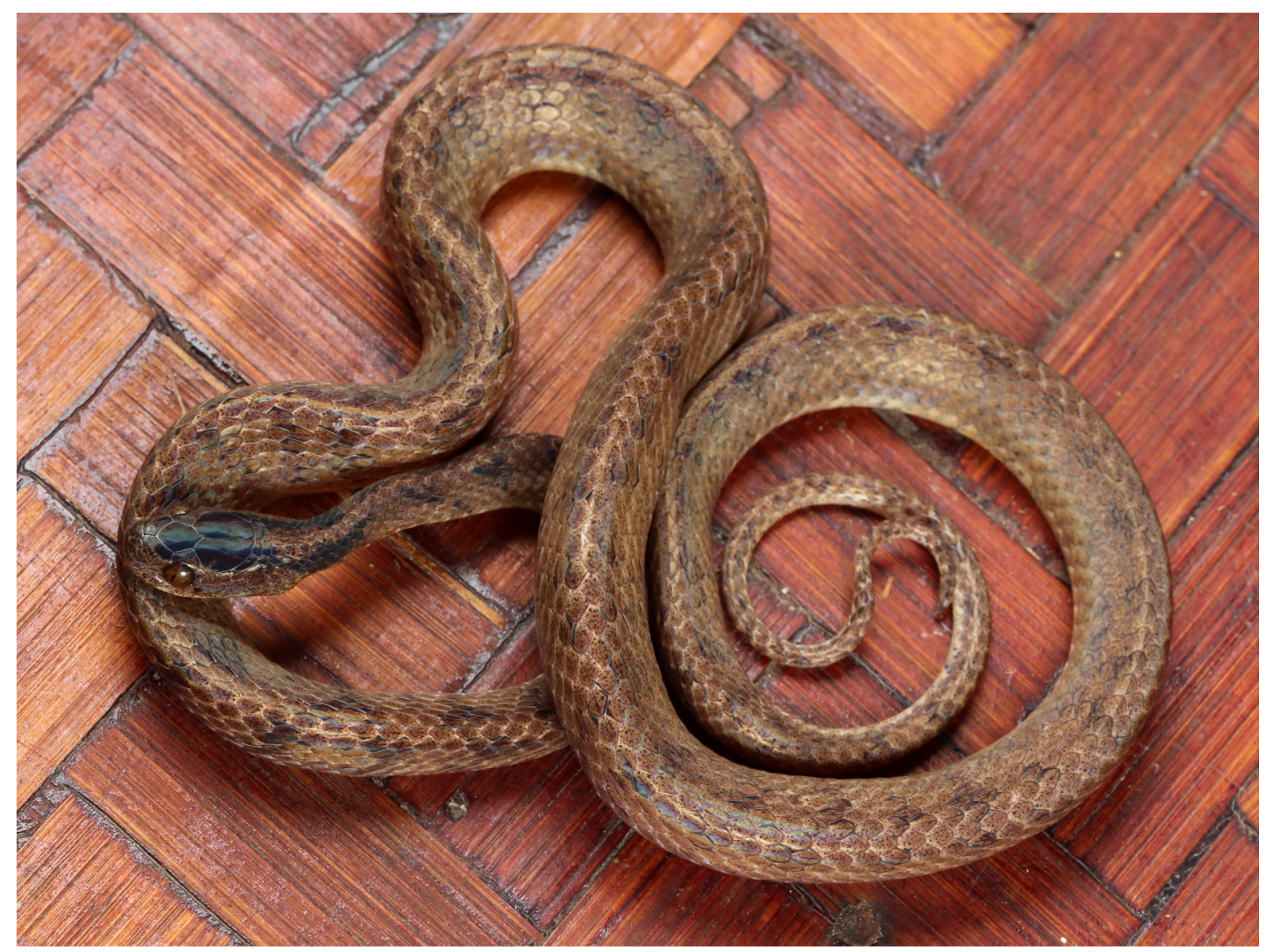

Fig. 1. Pareas kaduri sp. nov. Holotype, đ̊ (BNHS 3574) in life. Photograph by Zeeshan A. Mirza. 
Body laterally compressed, ventral surface a little flattened. Dorsal scales in 15:15:15 rows. Dorsal scales imbricate, regularly arranged, vertebral and adjoined scale rows enlarged and larger than the outermost dorsal scales. Eight scale rows on the mid-dorsum (including vertebral rows) keeled; other dorsal scale rows scales smooth and glossy, lacking apical pits. Ventral scales 160 in number +2 preventrals. Anal shield undivided, slightly larger than last ventral scale, its posterior margin overlaps nine small, irregular scales on each side, in addition to pair of larger subcaudals medially. Subcaudals paired, 70 in number. Tail terminates in a sharp tapering apical spine. Total length $694 \mathrm{~mm}$, tail length $144 \mathrm{~mm}$, tail/total length ratio 0.207 .

\section{Hemipenial morphology (paratype NCBS BH655)}

The organ is fully everted and expanded (Fig. 4). Hemipenis short, unilobed, stout and unicaliculate; lobe extends for about $60 \%$ of the hemipenis; capitulum restricted to sulcate and dorsal surfaces of the organ, covering nearly half of the lobe's length at the level of the sulcus spermaticus; capitulum smooth, except for two rows of calyces spanning almost the entire width of the organ; on asulcate surface, lobes ornamented with three to four parallel broken rows of mediolaterally enlarged and papillate body calyces; sulcus spermaticus simple; the sides of the sulcus spermaticus are smooth; truncus and hemipenial base is wrinkled and completely nude.

\section{Colouration in preservative (Fig. 2)}

Overall, in a shade of brown with 28 paired black transverse bands from nape to the vent. Some of these bands are distinct, whereas some are merely black spots that connect rudimentarily to form bands. The head bears a large black blotch from which two black longitudinal stripes (3-4 scales wide) run on each side of the neck leaving a pale central portion. The ventral scales are white or cream colored with sparse black mottling.

\section{Dentition (paratype, $\widehat{\jmath}$ NCBS BH655) (Fig. 5)}

Maxilla with six functional (12 total) on right and seven (14 total) on left teeth. All the teeth subequal, lacking a distinct diastema. Pterygoid with total of 6-7 teeth. Palatine with 13-14 functional (24-25 total) teeth that gradually decrease in size posteriorly. Mandibles with 21 and 23 (more than 50 total) functional dentary teeth of left and right, respectively.

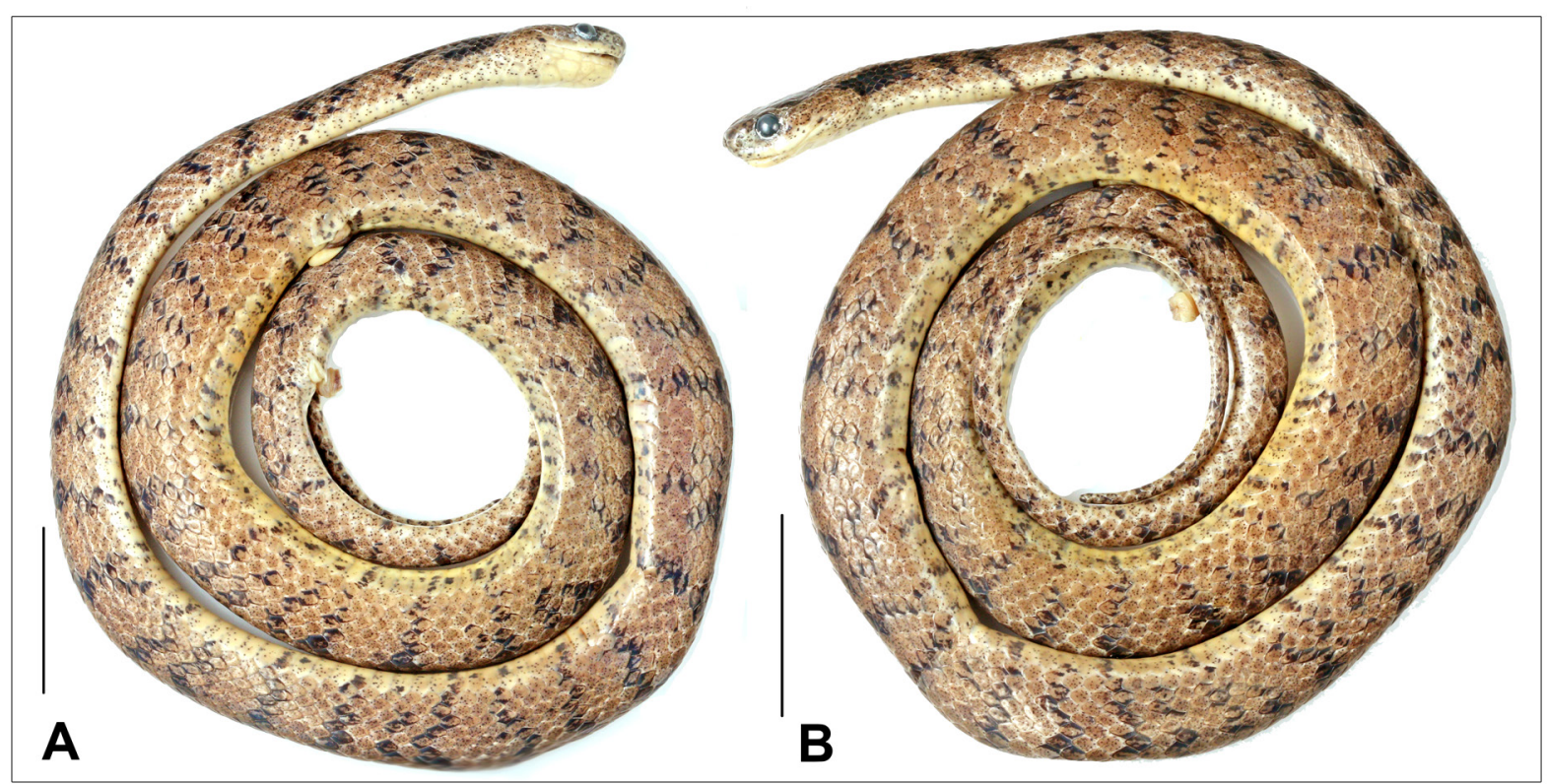

Fig. 2. Pareas kaduri sp. nov. Holotype, $\widehat{\partial}$ (BNHS 3574). A-B. Lateral views. Scale bars $=25 \mathrm{~mm}$. 


\section{Variation shown by paratypes and referred specimens}

The paratypes match the holotype in all respect except for the details noted herein: dorsal scales of female paratype BNHS 3575 are smooth, lacking keels, likely a character that is sexually dimorphic, in addition to fewer subcaudal scales. The color of individuals varies greatly in being light brown to dark blackish brown to reddish orange. Other differing characters are listed in Table 1.

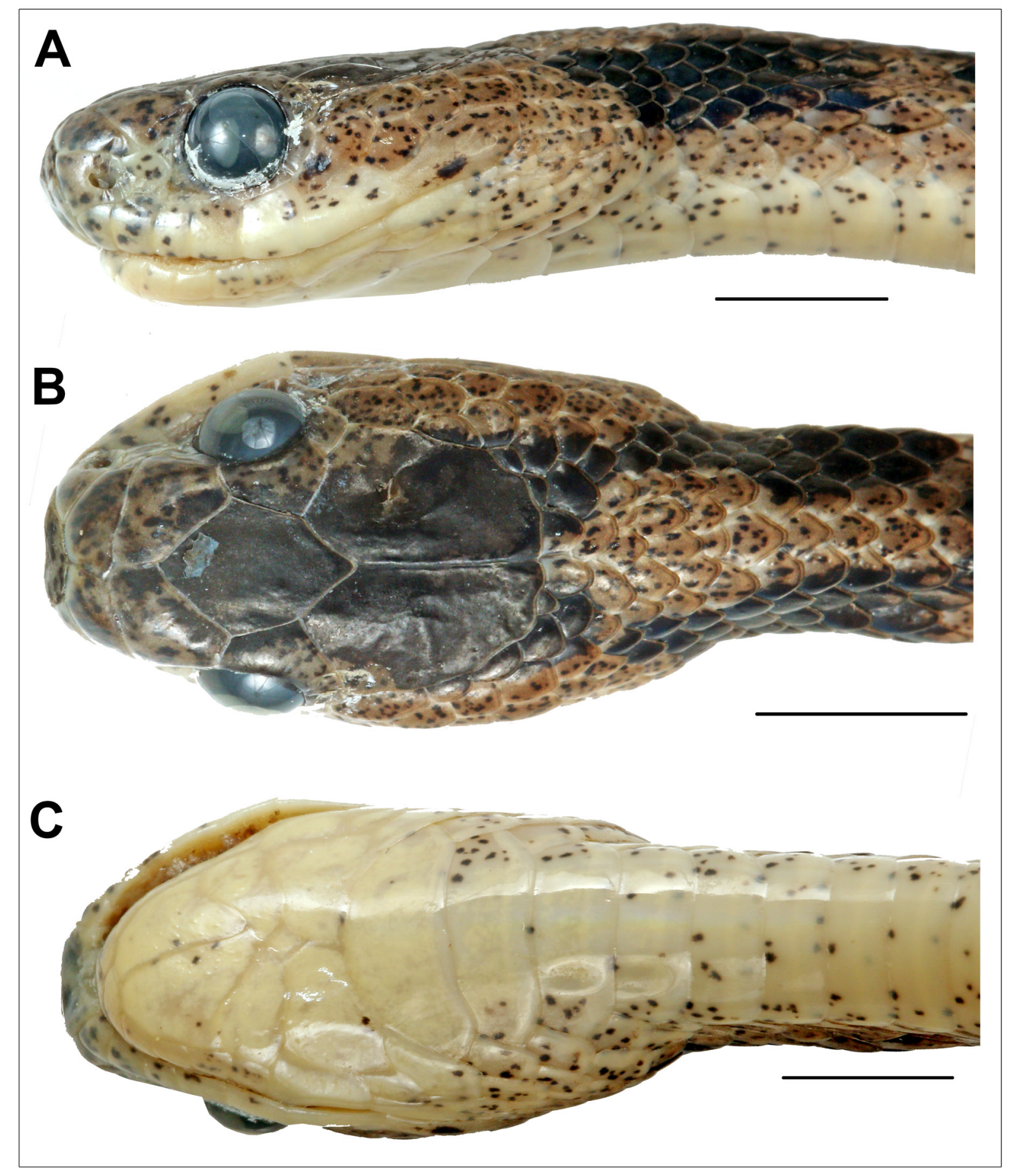

Fig. 3. Pareas kaduri sp. nov. Holotype, $\widehat{\jmath}$ (BNHS 3574). View of head. A. Left lateral view. B. Dorsal view. C. Ventral view. Scale bars $=5 \mathrm{~mm}$. 
Table 1. Morphometric and meristic data for the type series of Pareas kaduri sp. nov.

\begin{tabular}{|c|c|c|c|c|c|c|}
\hline & $\begin{array}{l}\text { BNHS } \\
3574\end{array}$ & BNHS 3575 & $\begin{array}{l}\text { NCBS } \\
\text { BH655 }\end{array}$ & $\begin{array}{l}\text { NCBS } \\
\text { BH656 }\end{array}$ & Range & Mean \\
\hline Sex & $\hat{\sigma}$ & q & 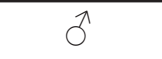 & $\hat{\sigma}$ & - & - \\
\hline TL & 694 & 597 & 571 & 668 & $571-694$ & 632.5 \\
\hline SVL & 550 & 484 & 455 & 545 & $455-550$ & 508.5 \\
\hline $\mathrm{TaL}$ & 144 & 113 & 116 & 123 & $113-144$ & 124 \\
\hline TaL/SVL & 0.262 & 0.233 & 0.255 & 0.226 & $0.226-0.262$ & 0.244 \\
\hline $\mathrm{Tal} / \mathrm{TL}$ & 0.207 & 0.189 & 0.203 & 0.184 & $0.184-0.207$ & 0.196 \\
\hline HL & 12 & 14.6 & 10.4 & 13.6 & $10.4-14.6$ & 12.8125 \\
\hline CL & 17.2 & 18.8 & 14.3 & 16.9 & $14.3-18.8$ & 16.7 \\
\hline HW & 8.8 & 6.8 & 7.1 & 7.9 & $7.1-8.8$ & 7.3625 \\
\hline ED & 3.5 & 3.6 & 2.7 & 3.2 & $2.7-3.6$ & 3.25 \\
\hline $\mathrm{El}$ & 1.8 & 1.8 & 1.5 & 1.8 & $1.5-1.8$ & 1.70625 \\
\hline ES & 3.8 & 4.3 & 3.7 & 3.8 & $3.7-4.3$ & 3.925 \\
\hline $\mathrm{EN}$ & 2.5 & 2.3 & 2.3 & 2.7 & $2.3-2.7$ & 2.4375 \\
\hline NW & 4.6 & 5.8 & 3.5 & 4.3 & $3.5-5.8$ & 4.5375 \\
\hline Ventrals & 160 & 171 & 182 & 183 & $160-183$ & 174 \\
\hline Subcaudals & 70 & 52 & 70 & 65 & $52-70$ & 64 \\
\hline DSR & $15: 15: 15$ & $15: 15: 15$ & $15: 15: 15$ & $15: 15: 15$ & - & - \\
\hline
\end{tabular}

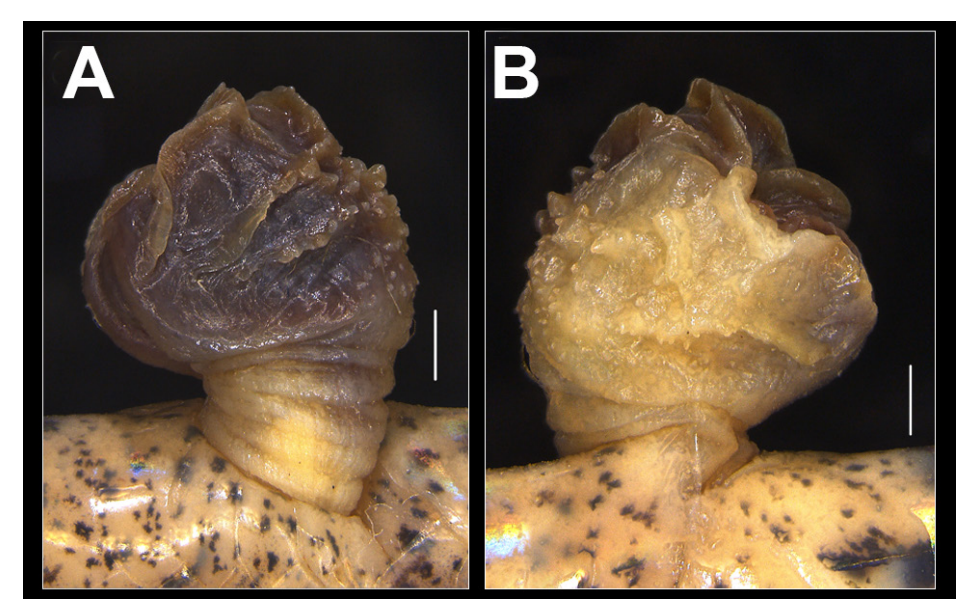

Fig. 4. Pareas kaduri sp. nov. Paratype, ồ (NCBS BH655). A-B. Hemipenis, lateral view. Scale bars = $1 \mathrm{~mm}$. 


\section{Genetic divergence}

Interspecific divergence observed is $12-24 \%$ for $c y t b$ and intraspecific genetic divergence is $1 \%$. (Appendix 2).

\section{Natural history}

The type specimens were captured on low bushes along roads on the outskirts of Kamlang Wildlife Sanctuary at night. All the specimens were observed actively foraging after dusk. The habitat at the type locality is contiguous with the adjoining Namdapha Tiger Reserve and Mehao Wildlife Sanctuary, which lie in the Mishmi Hill range. Mishmi Hills lie between the Himalayas and the Indo-Burma biodiversity hotspot. The adjoining areas of Myanmar also share similar biotope and it is likely that the new species will be distributed in Myanmar in addition to India. The species was found in sympatry with Pareas monticola, Boiga siamensis Nutaphand, 1971, Bungarus niger Wall, 1908, Ahetulla sp. and Trimeresurus popeiorum Smith, 1937. The new species is common throughout the sampled area ranging from an elevation of $300 \mathrm{~m}$ to $1200 \mathrm{~m}$, whereas $P$. monticola appears to be rare and only a single specimen was found at lower elevation $(<300 \mathrm{~m})$.

\section{Distribution}

Currently, the new species is known only form the type locality, a tropical wet evergreen forest.

\section{Discussion}

The phylogenetic relationships recovered in the present work based on 1117 bp of mitochondrial cytochrome b gene (Fig. 6) are congruent with those of other studies (You et al. 2015; Zaher et al. 2019; Vogel et al. 2020; Wang et al. 2020), in which the new species, P. kaduri sp. nov., is sister to the clade containing $P$. hamptoni, $P$. formosensis and P. mengziensis with high support (ML bootstrap 89, BI posterior probability 0.99 ). The new species differs from $P$. hamptoni and $P$. mengziensis in exhibiting an uncorrected pairwise sequence divergence of 12\% (Appendix 2). From other congeners,

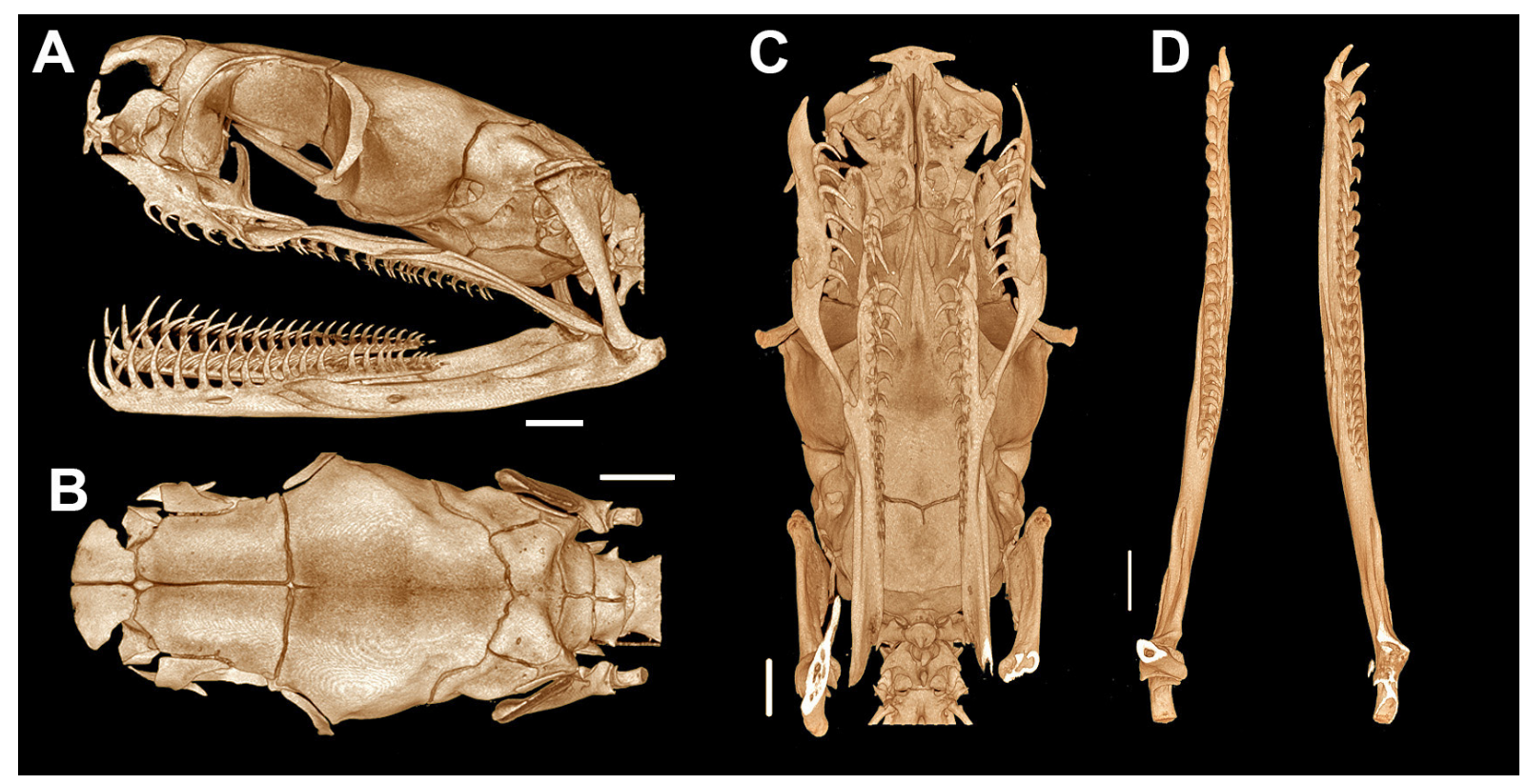

Fig. 5. Pareas kaduri sp. nov. Holotype, $\widehat{\partial}$ (BNHS 3574). Micro-CT scans of the head. A. Left lateral view. B. Dorsal view. C. Ventral view, without mandibles. D. Dorsal view of mandibles. Scale bars = $1 \mathrm{~mm}$. 


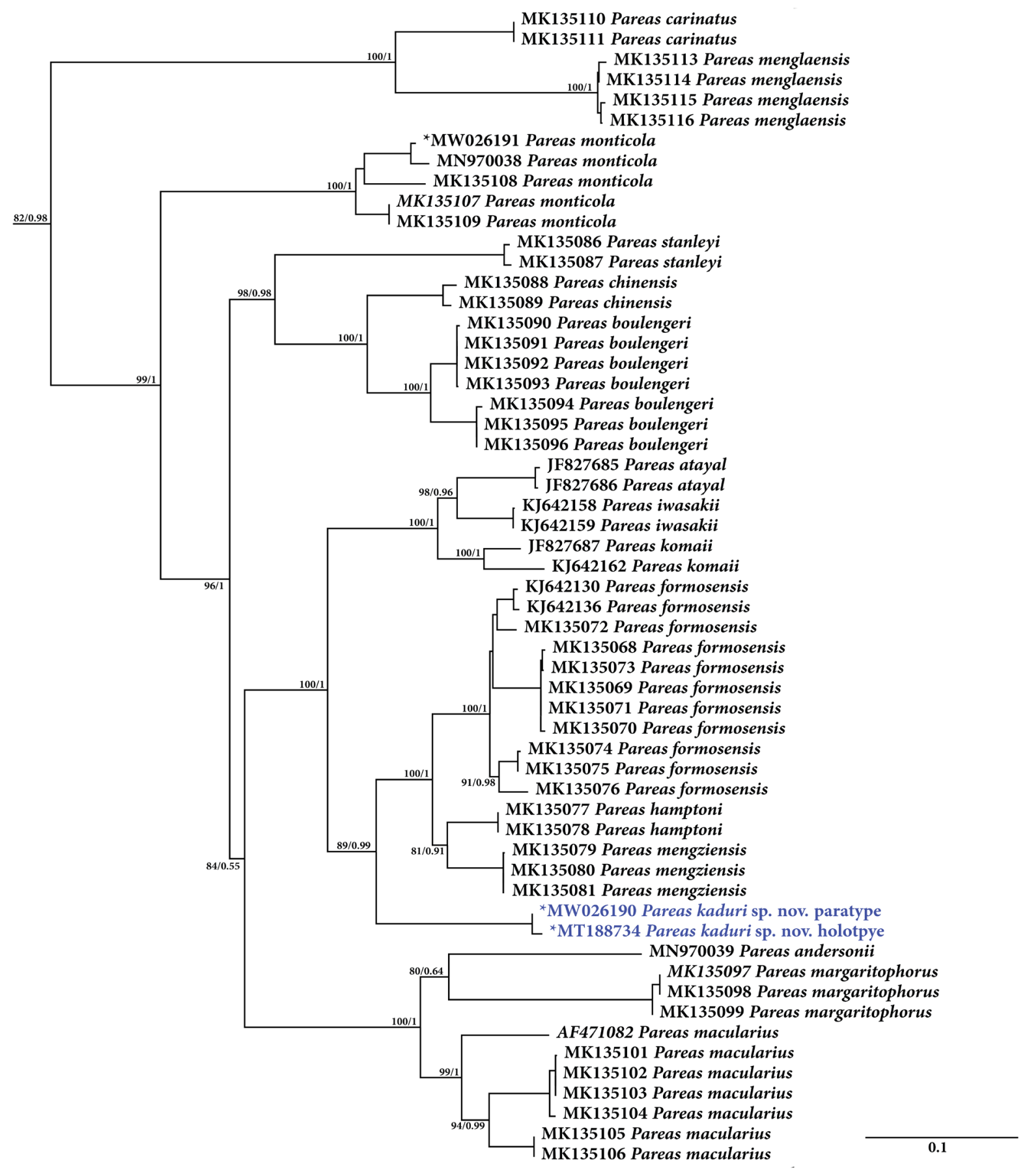

Fig. 6. ML phylogeny of Pareas based on partial sequences of the mitochondrial cyt $b$ gene generated through 1000 non-parametric bootstrap pseudoreplicates under the GTR + G model of sequence evolution. Numbers at nodes represent ML bootstrap support and BI posterior probability. For a complete tree see Appendix III. 
the new species shows an un-corrected p-distance of 13-24\% (Appendix 2). The molecular phylogeny based on 16S rRNA recovered similar relationships (Appendix 4). The genetic data hint at the presence of undocumented diversity within Pareas, especially in the broadly distributed species of the genus (see Vogel et al. 2020). Further work on the widespread members of Pareas must be undertaken to ascertain the taxonomic status of genetically distinct lineages. Discovery of the new species of Pareas of the $P$. hamptoni clade is the first record of a member of this clade in India and the basal relationship of the species in it hints at a Himalayan origin of the clade. Our work brings the total number of species recognized within the genus Pareas to 20 .

The discovery of yet another snake species from the same expedition to Arunachal Pradesh, after Trachischium apteii Bhosale, Gowande \& Mirza, 2019 (Bhosale et al. 2019) and Trimeresurus salazar Mirza, Bhosale, Phansalkar, Sawant, Gowande \& Patel, 2020 (Mirza et al. 2020), is not surprising as this region has received less attention in terms of documentation of diversity of reptiles. These discoveries advocate the need for extensive exploration across northeast India as a whole, to document the diversity of reptiles and perhaps other poorly studied taxa. Large expanses of forested habitats outside protected areas are under severe anthropogenic pressure and efforts must be made to safeguard these habitats especially in Arunachal Pradesh.

\section{Acknowledgments}

We thank the Forest Department of Arunachal Pradesh for issuing the necessary permits (Permit nos. CWL/Gen/173/2018-19/Pt.V11/2434-43 to ZM and CWL/Gen/173/2018-19/Pt.V11/2421-33 to GG) to conduct surveys across the state. Singinawa Conservation Foundation supported ZAM and Shripad Halbe (Brihad Bharatiya Samaj) supported HB and his team. We also thank Deepak Apte and Rahul Khot (BNHS) for his constant support. GG was supported by the Rufford Small Grants for Nature Conservation, for research on Indian agamids. GG is indebted to the Principal, Abasaheb Garware College, to the HoD, Annasaheb Kulkarni Department of Biodiversity, Abasaheb Garware College, and to the Principal, Fergusson College, and to the HoD, Biotechnology, Fergusson College and his advisor Dhanashree Paranjpe, for their constant support and encouragement. ZM thanks K. VijayRaghavan for guidance and all lab mates for their support. ZM wishes to acknowledge Kaushik Deuti (ZSI, Kolkata), Patrick Campbell (NHMUK, London), Nicholas Vidal (MNHN, Paris) for access to specimens and logistical support. Visit to museums would not have been possible without the help of the Infosys Travel Grant. Special thanks to an anonymous reviewer and Nikolay A. Poyarkov for their comments from which the manuscript greatly benefitted.

\section{Authors' contributions}

ZAM, HP, HB and GG designed the study; HB, PP, MS, GG and ZAM conducted fieldwork; ZAM and GG performed molecular analysis; ZAM, HP and GG wrote the paper. All authors read and approved the final manuscript.

\section{Disclosure statement}

No conflict of interest exists.

\section{Funding}

The work was supported by Singinawa Conservation Foundation, Shripad Halbe (Brihad Bharatiya Samaj) and The Rufford Foundation.

\section{References}

Anonymous 2015. The Deep Scaly Project, 2015, "Pareas hamptoni", Digital Morpholog. Available from http://digimorph.org/specimens/Pareas_hamptoni/ [accessed 26 Nov. 2019]. 
Bhosale H.S., Gowande G. \& Mirza Z.A. 2019. New species of fossorial natricid snakes of the genus Trachischium Günther, 1858 (Serpentes: Natricidae) from the Himalayas of northeast India. Comptes Rendus Biologies 342: 323-329. https://doi.org/10.1016/j.crvi.2019.10.003

Deepak V., Ruane S. \& Gower D.J. 2018. A new subfamily of fossorial colubroid snakes from the Western Ghats of peninsular India. Journal of Natural History 52: 2919-2934. https://doi.org/10.1080/00222933.2018.1557756

Dowling H. 1951. A proposed standard system of counting ventrals in snakes. British Journal of Herpetology 11: 97-99.

Heatwole H. 2009. Biology of the Reptilia. Volume 20, Morphology H, The Skull of Lepidosauria. Carl Gans, Abbot S. Gaunt, and Kraig Adler, editors. Integrative and Comparative Biology 49: 610-611. https://doi.org/10.1093/icb/icp063

Hoso M., Asami T. \& Hori M. 2007. Right-handed snakes: convergent evolution of asymmetry for functional specialization. Biology Letters 3: 169-172. https://doi.org/10.1098/rsbl.2006.0600

Kumar S., Stecher G., Li M., Knyaz C. \& Tamura K. 2018. MEGA X: Molecular Evolutionary Genetics Analysis across computing platforms. Molecular Biology and Evolution 35: 1547-1549.

https://doi.org/10.1093/molbev/msy096

Lalbiakzuala \& Lalremsanga H.T. 2019. Pareas margaritophorus, a new country report for India. Herpetological Review 50: 332.

Lanfear R., Calcott B., Ho S. \& Guindon S. 2012. PartitionFinder: combined selection of partitioning schemes and substitution models for phylogenetic analyses. Molecular Biology and Evolution 29: 16951701. https://doi.org/10.1093/molbev/mss020

Leary S., Underwood W., Anthony R. \& Cartner S. 2013. AVMA Guidelines for the Euthanasia of Animals: 2013 edition. American Veterinary Medical Association, Schaumburg, IL, USA.

Mirza Z.A. \& Patel H. 2018. Back from the dead! Resurrection and revalidation of the Indian endemic snake genus Wallophis Werner, 1929 (Squamata: Colubridae) insights from molecular data. Mitochondrial DNA Part A: DNA Mapping, Sequencing, and Analysis 29: 331-334.

https://doi.org/10.1080/24701394.2016.1278536

Mirza Z.A., Vyas R., Patel H., Maheta J. \& Sanap R.V. 2016. A new Miocene-divergent lineage of Old World racer snake from India. PloS ONE 11 (3): e0148380.

https://doi.org/10.1371/journal.pone.0148380

Mirza Z.A., Bhosale H.S., Phansalkar P.U., Sawant M., Gowande G.G. \& Patel H. 2020. A new species of green pit vipers of the genus Trimeresurus Lacépède, 1804 (Reptilia: Serpentes: Viperidae) from western Arunachal Pradesh, India. Zoosystematics and Evolution 96: 123-138.

https://doi.org/10.3897/zse.96.48431

Pyron R.A., Kandambi H.K.D., Hendry C.R., Pushpamal V., Burbrink F.T. \& Somaweera R. 2013. Genus-level phylogeny of snakes reveals the origins of species richness in Sri Lanka. Molecular Phylogenetics and Evolution 66: 969-978. https://doi.org/10.1016/j.ympev.2012.12.004

Ronquist F. \& Huelsenbeck J. 2003. MrBayes 3: Bayesian phylogenetic inference under mixed models. Bioinformatics 19: 1572-1574. https://doi.org/10.1093/bioinformatics/btg180

Thompson J.D., Gibson T.J. \& Higgins D.G. 2002. Multiple sequence alignment using ClustalW and ClustalX. Current Protocols in Bioinformatics 0: 2.3.1-2.3.22.

https://doi.org/10.1002/0471250953.bi0203s00 
Trifinopoulos J., Nguyen L., von Haeseler A. \& Minh B.Q. 2016. W-IQ-TREE: a fast online phylogenetic tool for maximum likelihood analysis. Nucleic Acids Research 44: W232-W235.

https://doi.org/10.1093/nar/gkw256

Vitt L.J. \& Caldwell J.P. 2014. Chapter 2 - Anatomy of Amphibians and Reptiles. In: Vitt L.J. \& Caldwell J.P. (eds) Herpetology: An Introductory Biology of Amphibians and Reptiles: 35-82. Academic Press, San Diego. https://doi.org/10.1016/B978-0-12-386919-7.00002-2

Vogel G. 2015. A new montane species of the genus Pareas Wagler, 1830 (Squamata: Pareatidae) from Northern Myanmar. TAPROBANICA: The Journal of Asian Biodiversity 7: 1-7.

https://doi.org/10.4038/tapro.v7i1.7501

Vogel G., Nguyen T. van, Lalremsanga H.T., Biakzuala L., Hrima V. \& Poyarkov N.A. 2020. Taxonomic reassessment of the Pareas margaritiferus-macularius species complex (Squamata, Pareidae). Vertebrate Zoology 70: 547-569. https://doi.org/10.26049/VZ70-4-2020-02

Wallach V., Williams K.L. \& Boundy J. 2014. Snakes of the World: A Catalogue of Living and Extinct Species. Taylor \& Francis Group, London. https://doi.org/10.1201/b16901

Wang P., Che J., Liu Q., Li K., Jin J.Q., Jiang K., Shi L. \& Guo P. 2020. A revised taxonomy of Asian snail-eating snakes Pareas (Squamata, Pareidae): evidence from morphological comparison and molecular phylogeny. ZooKeys 939: 45-64. https://doi.org/10.3897/zookeys.939.49309.

Whitaker R. \& Captain A. 2004. Snakes of India. The Field Guide. Draco Books, Chennai.

You C.W., Poyarkov N.A. \& Lin S.M. 2015. Diversity of the snail-eating snakes Pareas (Serpentes, Pareatidae) from Taiwan. Zoologica Scripta 44: 349-361. https://doi.org/10.1111/zsc.12111

Zaher H., Murphy R.W., Arredondo J.C., Graboski R., Machado-Filho P.R., Mahlow K., Montingelli G.G., Quadros A.B., Orlov N.L., Wilkinson M., Zhang Y.P. \& Grazziotin F.G. 2019. Large-scale molecular phylogeny, morphology, divergence-time estimation, and the fossil record of advanced caenophidian snakes (Squamata: Serpentes). PLoS ONE 14 (5): e0216148.

https://doi.org/10.1371/journal.pone.0216148

Manuscript received: 5 July 2020

Manuscript accepted: 25 October 2020

Published on: 17 December 2020

Topic editor: Rudy Jocqué

Desk editor: Pepe Fernández

Printed versions of all papers are also deposited in the libraries of the institutes that are members of the EJT consortium: Muséum national d'histoire naturelle, Paris, France; Meise Botanic Garden, Belgium; Royal Museum for Central Africa, Tervuren, Belgium; Royal Belgian Institute of Natural Sciences, Brussels, Belgium; Natural History Museum of Denmark, Copenhagen, Denmark; Naturalis Biodiversity Center, Leiden, the Netherlands; Museo Nacional de Ciencias Naturales-CSIC, Madrid, Spain; Real Jardín Botánico de Madrid CSIC, Spain; Zoological Research Museum Alexander Koenig, Bonn, Germany; National Museum, Prague, Czech Republic. 
Appendix 1 (continued on next page). Details of species and accession numbers used in the present work based on Wang et al. (2020).

\begin{tabular}{|c|c|c|c|}
\hline Taxon & $\begin{array}{l}\text { Voucher } \\
\text { number }\end{array}$ & Locality & $\begin{array}{c}\text { GenBank } \\
\text { accession number }\end{array}$ \\
\hline Pareas formosensis & YBU 12015 & Hainan, China & MK135068 \\
\hline P. formosensis & GP 2164 & Hainan, China & MK135069 \\
\hline P. formosensis & GP 2165 & Hainan, China & MK135070 \\
\hline P. formosensis & YBU 12032 & Hainan, China & MK135071 \\
\hline P. formosensis & GP 4581 & Jingning, Zhejiang, China & MK135072 \\
\hline P. formosensis & YBU 17029 & Hainan, China & MK135073 \\
\hline P. formosensis & YBU 12090 & Leishan, Guizhou, China & MK135074 \\
\hline P. formosensis & YBU 12115 & Rongjiang, Guizhou, China & MK135075 \\
\hline P. formosensis & YBU 14508 & Guangxi, China & MK135076 \\
\hline P. formosensis & GP 3696 & Yanshan, Jiangxi, China & HM46857 \\
\hline P. formosensis & GP 3808 & Yanshan, Jiangxi, China & HM46858 \\
\hline P. formosensis & YBU 14573 & Yanshan, Jiangxi, China & HM46859 \\
\hline P. formosensis & NMNS 05632 & N. Cross-Is. Highway, Taiwan, China & KJ642130 \\
\hline P. formosensis & NMNS 05637 & Xitou, Nantou, Taiwan, China & KJ642136 \\
\hline P. hamptoni & YPX 18219 & Myanmar & MK135077 \\
\hline P. hamptoni & YPX 18604 & Myanmar & MK135078 \\
\hline P. mengziensis & GP 1294 & Mengzi, Yunnan, China & MK135079 \\
\hline P. mengziensis & YBU 14251 & Mengzi, Yunnan, China & MK135080 \\
\hline P. mengziensis & YBU 14252 & Mengzi, Yunnan, China & MK135081 \\
\hline P. mengziensis & YBU 14253 & Mengzi, Yunnan, China & MK135082 \\
\hline P. mengziensis & YBU 14288 & Mengzi, Yunnan, China & MK135083 \\
\hline P. mengziensis & YBU 15100 & Kaiyuan, Yunnan, China & MK135084 \\
\hline P. mengziensis & YBU 15114 & Kaiyuan, Yunnan, China & MK135085 \\
\hline P. stanleyi & GP 229 & Guangxi, China & MK135086 \\
\hline P. stanleyi & YBU 12094 & Leishan, Guizhou, China & MK135087 \\
\hline P. chinensis & GP 2196 & Junlian, Sichuan, China & MK135088 \\
\hline P. chinensis & GP 2383 & Hongya, Sichuan, China & MK135089 \\
\hline P. boulengeri & GP 2923 & Jiangkou, Guizhou, China & MK135090 \\
\hline P. boulengeri & GP 207 & Anxian, Sichuan, China & MK135091 \\
\hline P. boulengeri & YBU 13323A & Wufeng, Hubei, China & MK135092 \\
\hline P. boulengeri & GP 4716 & Yidu, Hubei, China & MK135093 \\
\hline P. boulengeri & GP 3428 & Yixian, Anhui, China & MK135094 \\
\hline P. boulengeri & YBU 17155 & Chunan, Zhejiang, China & MK135095 \\
\hline P. boulengeri & YBU 17245 & Chunan, Zhejiang, China & MK135096 \\
\hline P. margaritophorus & YBU 16061 & Cangwu, Guangxi, China & MK135097 \\
\hline P. margaritophorus & YBU 17164 & Cangwu, Guangxi, China & MK135098 \\
\hline P. margaritophorus & GP 4437 & Cangwu, Guangxi, China & MK135099 \\
\hline P. margaritophorus & YBU 16095 & Cangwu, Guangxi, China & MK135100 \\
\hline P. macularius & GP815 & Hainan, China & MK135101 \\
\hline
\end{tabular}


Appendix 1 (continued).

\begin{tabular}{|c|c|c|c|}
\hline Taxon & $\begin{array}{l}\text { Voucher } \\
\text { number }\end{array}$ & Locality & $\begin{array}{c}\text { GenBank } \\
\text { accession number }\end{array}$ \\
\hline P. macularius & GP 2110 & Hainan, China & MK135102 \\
\hline P. macularius & YBU 12016 & Hainan, China & MK135103 \\
\hline P. macularius & YBU 17030 & Hainan, China & MK135104 \\
\hline P. macularius & YBU 17078 & Jingdong, Yunnan, China & MK135105 \\
\hline P. macularius & YBU 17062 & Jingdong, Yunnan, China & MK135106 \\
\hline P. monticola & GP 2027 & Motuo, Xizang, China & MK135107 \\
\hline P. monticola & KIZ 047036 & Pingbian, Yunnan, China & MK135108 \\
\hline P. monticola & KIZ 014167 & Motuo, Xizang, China & MK135109 \\
\hline P. carinatus & GP 1079 & Malaysia & MK135110 \\
\hline P. carinatus & KIZ 011972 & Malaysia & MK135111 \\
\hline P. carinatus & KIZ 011970 & Malaysia & MK135112 \\
\hline P. menglaensis & GP 1292 & Mengla, Yunnan, China & MK135113 \\
\hline P. menglaensis & YBU 14124 & Mengla, Yunnan, China & MK135114 \\
\hline P. menglaensis & YBU 14141 & Mengla, Yunnan, China & MK135115 \\
\hline P. menglaensis & YBU 14142 & Mengla, Yunnan, China & MK135116 \\
\hline P. atayal 1 & HC 000618 & N. Cross-Is. Highway, Taiwan, China & JF827685 \\
\hline P. atayal 2 & HC 000628 & N. Cross-Is. Highway, Taiwan, China & JF827686 \\
\hline P. komaii 1 & HC 000669 & Lijia, Taidong, Taiwan, China & JF827687 \\
\hline P. komaii 2 & NMNS 05598 & Daxueshan, Taichung, Taiwan, China & KJ642162 \\
\hline P. iwasakii 1 & I03-ISG1 & Ishigaki Is., S. Ryukyu, Japan & KJ642158 \\
\hline P. iwasakii 2 & I04-ISG2 & Ishigaki Is., S. Ryukyu, Japan & KJ642159 \\
\hline P. macularius & CAS 206620 & Bago Division, Myanmar & AF471082 \\
\hline Aplopeltura boa 1 & KIZ 011963 & Malaysia & JF827673 \\
\hline A. boa 2 & LSUHC 7248 & Malaysia & KC916746 \\
\hline Asthenodipsas laevis & LSUHC 10346 & Peninsular Malaysia & KC916749 \\
\hline A. malaccanus & FMNH 273617 & - & KX660469 \\
\hline A. vertebralis 1 & LSUHC 9138 & Peninsular Malaysia & KC916754 \\
\hline A. vertebralis 2 & LSUHC 9873 & Peninsular Malaysia & KC916753 \\
\hline A. lasgalenensis 1 & 10668 & Peninsular Malaysia & KC916776 \\
\hline A. lasgalenensis 2 & 7228 & Peninsular Malaysia & KC916769 \\
\hline A. tropidonotus & & Sumatra, Indonesia & AY425808 \\
\hline X. stenorhynchus & CAS 17199 & India & MK340915 \\
\hline X. captaini & BNHS 3376 & Kottayam, Kerala, India & MK340914 \\
\hline Lycodon rufozonatum & GP 625 & Dandong, Liaoning, China & KC733196 \\
\hline Gloydius brevicaudus & GP1099 & Dalian, Liaoning, China & JQ687497 \\
\hline Xenodermus javanicus & FMNH 230073 & Malaysia & AY425810 \\
\hline
\end{tabular}




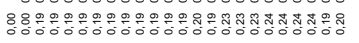

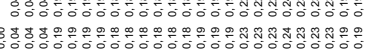

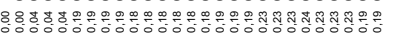

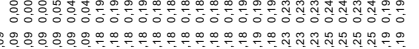

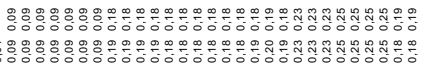

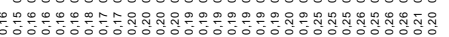
5

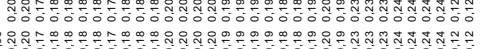

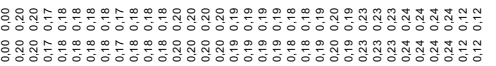

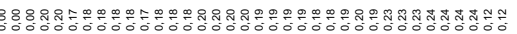

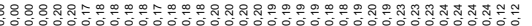

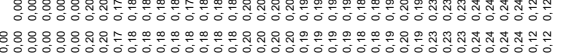

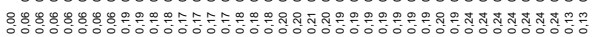

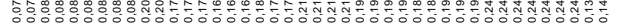

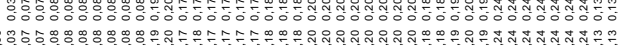

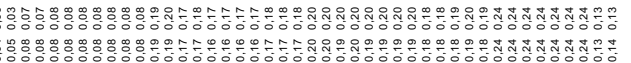

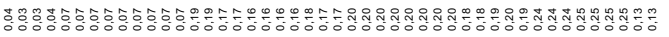
等

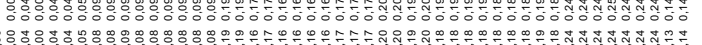
等

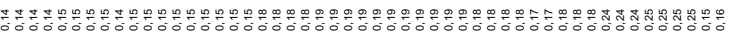
等

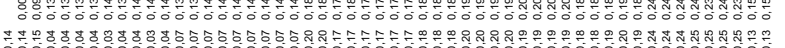

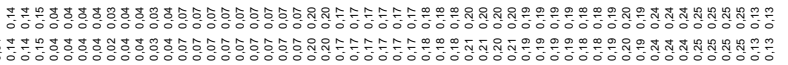

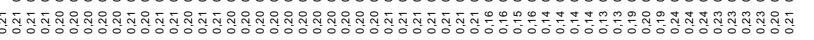
긋음은은

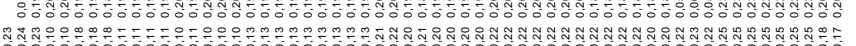

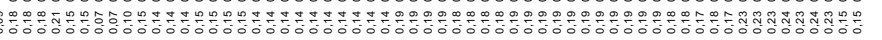

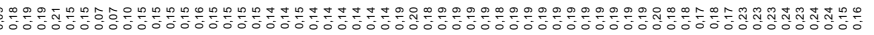

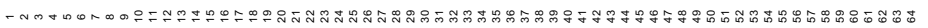


Appendix 3. ML phylogeny of selected members of Pareinae Romer, 1956 based on partial sequences of mitochondrial cyt $b$ gene generated through 1000 non-parametric bootstrap pseudoreplicates under the GTR + G model of sequence evolution. Numbers at nodes represent ML bootstrap support and BI posterior probability.

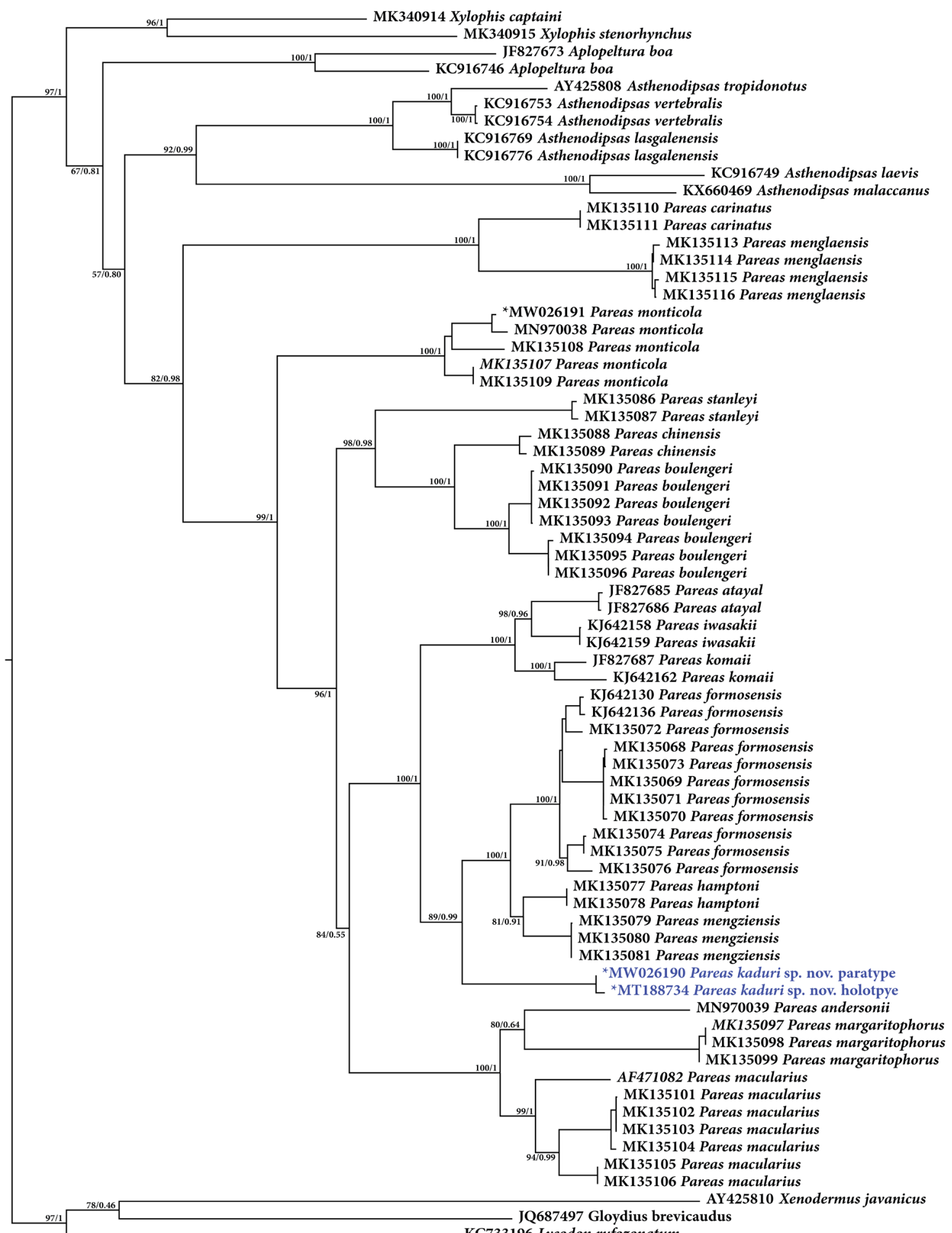


Appendix 4. ML phylogeny of selected members of Pareinae Romer, 1956 based on partial sequences of mitochondrial 16S rRNA gene generated through 1000 non-parametric bootstrap pseudoreplicates under the GTR + G model of sequence evolution. Numbers at nodes represent ML bootstrap support and BI posterior probability.

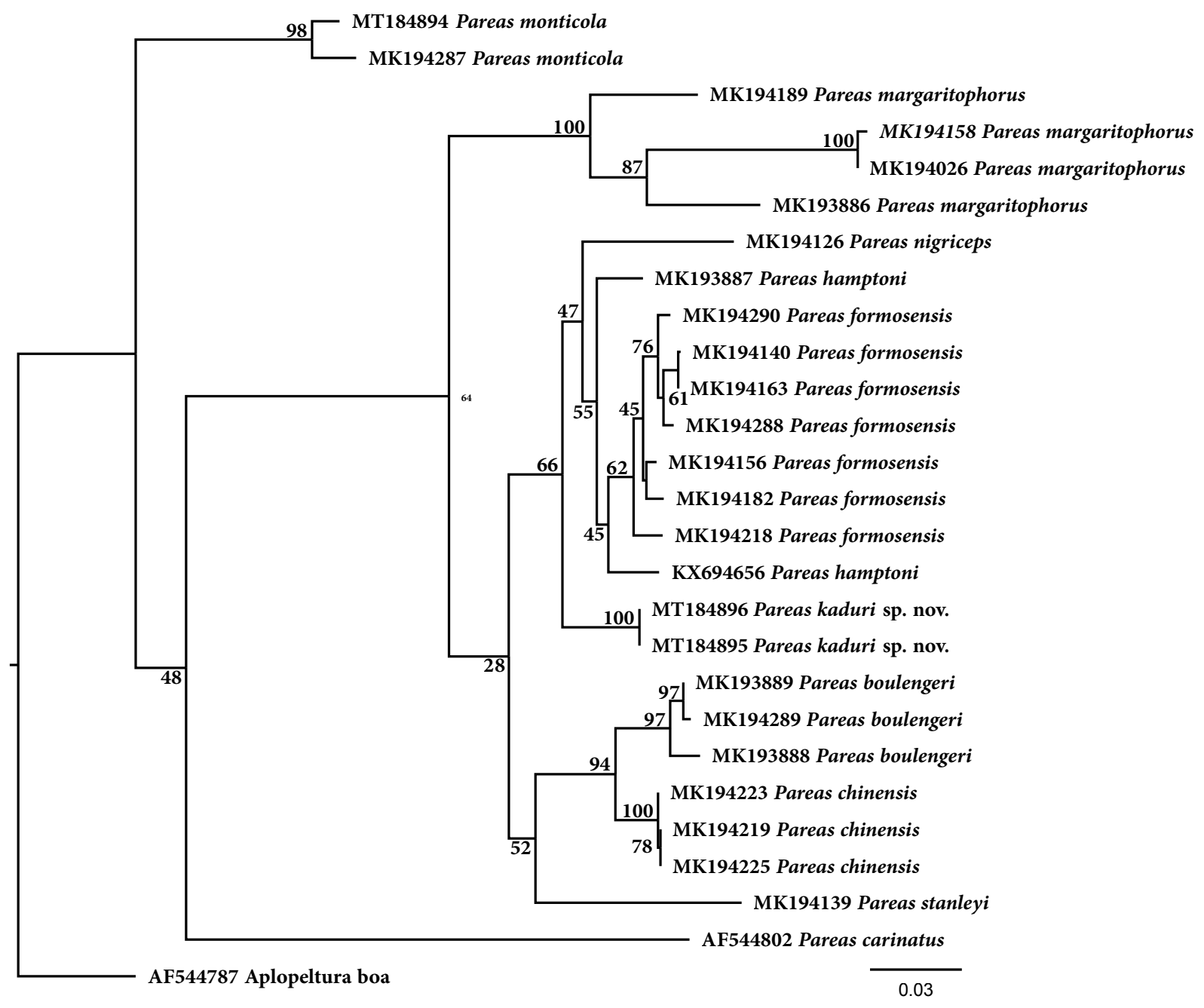


Appendix 5. Comparative material examined.

Pareas carinatus (Wagler, 1830) (= Pareas berdmorei Theobald, 1868)

MYANMAR • 2 specs, syntypes; “Tenasserim” (in southern Myanmar); ZSI 8021, ZSI 8022.

Pareas hamptoni (Boulenger, 1905)

MYANMAR • 1 spec., Mogok, Upper Burma [= Myanmar]; NHMUK 1946.1.20.16 • 3 specs; Burma; NHMUK 1974.899, NHMUK 1974.231, NHMUK 1974.232.

CHINA • 1 spec.; Hainan; NHMUK 1937.2.1.18.

Pareas macularius Theobald, 1868

MYANMAR • 1 spec., syntype; "Tenasserim” [= Tanintharyi Div., S Myanmar]; NHMUK 1946.1.20.8.

Pareas monticola (Cantor, 1839)

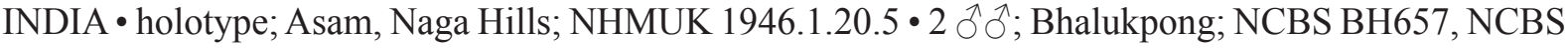
BH658 • 1 o ; Sonai Rupai Wildlife Sanctuary; NCBS BH659 • 1 o; Arunachal Pradesh, Kamlang Wildlife Sanctuary; NCBS BH660 • 1 spec.; West Bengal, Darjeeling District; ZSI 21021.

Pareas stanleyi (Boulenger, 1914)

CHINA • holotype; N.W. Fokien; NHMUK 1946.1.20.4.

Amblycephalus tokinensis (Angel, 1920)

VIETNAM • holotype; Haut Tonkin; MNHN-RA-1908.206. 